\title{
The combined effects of dosage level and interstimulus interval on the formation of one-trial poison-based aversions in rats
}

\author{
EMIR ANNE ANDREWS and NORMAN S. BRAVEMAN \\ Memorial University of Newfoundland, St. John's, Newfoundland AIC $5 S 7$
}

\begin{abstract}
Adult male rats were allowed to drink a novel solution of sodium saccharin which was followed .5, $1.5,4.5,7.0,13.5$, or $24.0 \mathrm{~h}$ later by intubation of a $.9,2.7,8.1$, or $12.15 \%(\mathrm{w} / \mathrm{v})$ solution of sodium chloride $(\mathrm{NaCl})$. Three days after the single training trial, consumption of saccharin was again measured. Significant differences between groups were found. When consumption by the experimental groups at each CS-UCS delay was compared with that of the isotonic $\mathrm{NaCl}(.9 \%)$ control group, it was found that all groups showed aversions at delays of $.5,1.5$, and $4.5 \mathrm{~h}$. Animals intubated with $8.1 \%$ or $12.15 \% \mathrm{NaCl}$ solution also showed aversions at a delay of $7.0 \mathrm{~h}$, and those intubated with the $12.15 \%$ solution showed an aversion at a delay of $13.5 \mathrm{~h}$. No $\mathrm{NaCl}$ concentration used produced aversions at a CS-UCS interval of 24.0. These results reflect differences in the effectiveness of a range of $\mathrm{NaCl}$ concentrations in producing one-trial aversions at long CS-UCS intervals.
\end{abstract}

The paradigm used to demonstrate poison-based avoidance learning is a simple one. Ingestion of a harmless food (CS) is followed, after some period of time, by sickness (UCS). Upon complete recovery from the sickness, subjects are allowed to consume the same food substance and, when comparisons are made with appropriate controls, it is typically found that they now avoid the food which preceded the induced illness. It is now well established that long delay poison-based aversions are a.form of learning and not an artifact of the experimental situation (see Revusky \& Garcia, 1970). Several explanations, all based in one form or another on some aspect of the relationship between the taste and the sickness, have been proposed to explain why it is possible to obtain associations with only one trial and with long delays between the CS and the UCS using the poison-based avoidance learning paradigm but not with more traditional ones. For example, the principle of stimulus relevance stated that "certain associations are formed more easily if the events to be associated are capable of being perceived as belonging together (Capretta, 1961, p. 241)." That is, certain events such as eating and illness are more easily perceived by the learner as belonging together than are other events such as eating and shock. As a result, eating and illness are readily associated and, since the events are "relevant" for the learner, they can be associated even if the delay between them is several minutes or hours (Revusky, 1971).

This research formed part of a thesis submitted by the first author as part of the requirements for a Master of Science degree, Memorial University of New foundland, 1973. The first author was supported in part by a National Research Council Scholarship for 1971-1972 (File No. 1560). The authors wish to thank Drs. Samuel Revusky and Carolyn Harley for their advice on various aspects of the study. Portions of this study were presented at the 35th Annual Meeting of the Canadian Psychological Association, June 1974 at Winsor, Ontario.
The principle of relevance has been used as an explanation for one-trial long delay learning (Revusky \& Garcia, 1970) in spite of the fact that the original procedure used to demonstrate the relevance principle employed neither long CS-UCS intervals nor a one-trial learning situation (Braveman \& Capretta, 1965; Capretta, 1961). The technique used by Braveman and Capretta (1965), for example, involved preference testing rats with a sugar and sugar-saccharin solution for 5 days prior to training. On 5 of the training days, experimental subjects received a stomach preload of $\mathrm{NaCl}$ followed by access to their preferred solution, while on 5 alternate days they received a stomach preload of plain water and access to their nonpreferred solution. Preloading subjects in this manner insured that the shortest possible CS-UCS interval was used, i.e., the UCS immediately preceded the CS so that sickness was contiguous with consumption of the CS. Subjects were then given two more daily preference tests with the solutions.

In two pilot studies, the present investigators showed that long delay learning could in fact occur with intubated $\mathrm{NaCl}$ as the UCS, but the conditions of the studies did not allow an evaluation of the aversion after only one training trial. Also, the results of these studies were equivocal with respect to the finding of a delay of punishment gradient. That is, the findings from one study showed that aversions were stronger with a $1-\mathrm{h}$ delay than with a $5 \cdot h$ delay, while, in the second study, animals made sick $7 \mathrm{~h}$ after consumption of their preferred solution formed aversions that were as strong as those formed by animals trained with a 1-h delay.

The inability to find a clear-cut gradient of punishment was of particular interest since the occurrence of these gradients has been one of the strongest arguments in support of the view that long 


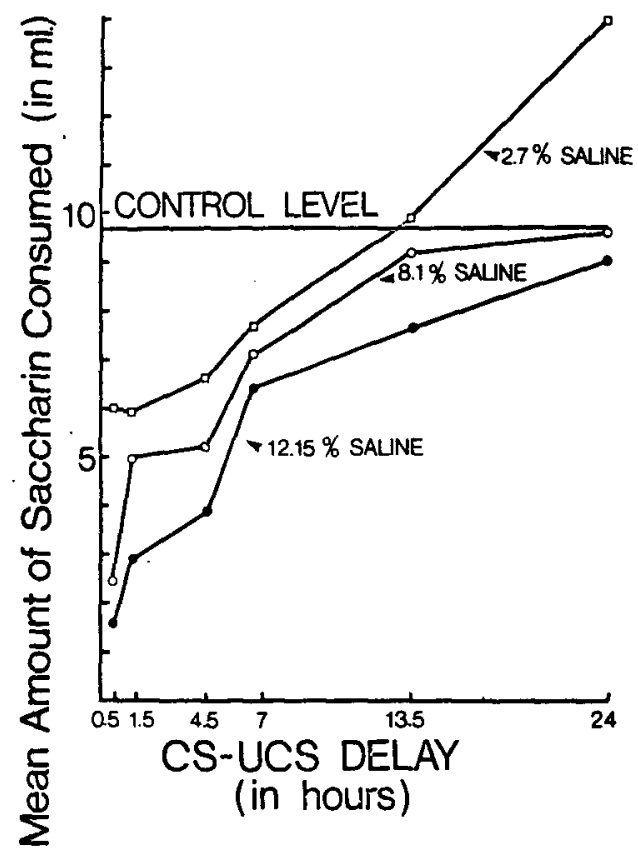

Figure 1. Mean saccharin consumption of all groups on posttraining preference test day.

delay aversions are not different from more typical forms of learning. Also, delay of punishment gradients have been shown to be a general characteristic of other toxins (see Revusky, 1971). Thus, while findings from experiments which use the $\mathrm{NaCl}$ intubation method have been used as the basis for a learning interpretation of poison-based aversions, it was not possible to obtain a clear-cut delay of punishment gradient when this method was used.

It is possible that floor effects may have obscured the delay of punishment gradient in the two preliminary studies. That is to say, the use of too many training trials, the use of CS-UCS intervals which were not long enough, or the use of a very intense UCS could have produced maximal aversions in all animals and thus would have obscured a gradient. For example, a toxin that might have produced weaker aversions with a $7 \cdot \mathrm{h}$ CS-UCS interval than with a 1 -h interval using one training trial may have produced aversions of equal strength if several training trials were used. It is also possible that sufficiently long CS-UCS intervals were not used in the preliminary studies so that maximal aversions were produced in all animals. Finally, the use of a very intense UCS could have led to floor effects. Pilot studies by the present investigators showed that intubation of a $\mathrm{NaCl}$ solution more concentrated than $13.0 \%(\mathrm{w} / \mathrm{v})$ was fatal in water-deprived rats. Hence, the $10.0 \%(\mathrm{w} / \mathrm{v})$ concentration used in the two preliminary studies was a fairly intense UCS and may have produced so severe an illness that, when combined with repeated training trials and CS.UCS intervals of only moderate duration, maximum aversions were obtained. To correct for these possible defects, the present study involved the use of one CS-UCS trial as well as factorial combinations of a number of $\mathrm{NaCl}$ concentrations and CS-UCS intervals.

\section{METHOD}

\section{Subjects}

The subjects were 180 experimentally naive male albino rats, 90 days old at the start of the experiment, obtained from the Canadian Breeding Farms. Animals were maintained in individual cages on ad-lib food throughout the experiment. Six subjects died during the experiment and were replaced in later replications so that there were between six and eight subjects in each experimental and control group.

\section{Procedure}

All subjects were adapted to a water-deprivation schedule on which they received water for $10 \mathrm{~min}$ each day in their home cages. After 6 days, all animals had reached a stable level of consumption. The single training trial took place on the next day, at which time all subjects received $.5 \%(\mathrm{w} / \mathrm{v})$ sodium saccharin during their $10 \mathrm{~min}$ drinking period. Then, after a CS-UCS interval of $.5,1.5,4.5,7.0,13.5$, or $24.0 \mathrm{~h}$, treatment groups were intubated with a $1.5 \%$ body weight dose of $2.7,8.1$, or $12.15 \%(w / v) ~ \mathrm{NaCl}$. As a control for the intubation procedure, groups of animals were intubated, after the same CS-UCS intervals, with a $1.5 \%$ body weight dose of a nontoxic isotonic $(.9 \%) \mathrm{NaCl}$ solution. Intubation was accomplished by holding the subject's mouth open with a rubber brace (cut from a one-hole hard-rubber stopper) and inserting a catheter directly into the subject's stomach. The tip of the catheter was first dipped in water to encourage the animal to swallow. Once the catheter was in the animal's stomach, the $\mathrm{NaCl}$ was injected slowly by means of a syringe attached to the catheter. Two hours after the $\mathrm{NaCl}$ intubation, all subjects received water for $6 \mathrm{~h}$ to facilitate recovery from the $\mathrm{NaCl}$-induced illness. Forty-eight hours after animals had received saccharin on the training day, all subjects were returned to a $10-\mathrm{min} /$ day water schedule. The following day, all subjects received a 10-min drinking trial with saccharin. The amount of water or saccharin consumed on each day was recorded to the nearest $.5 \mathrm{ml}$.

\section{RESULTS}

A one-way analysis of variance (Winer, 1962) showed that saccharin consumption on the training day, prior to sickness, was equivalent for all groups $(F=.81$, $\mathrm{df}=23,156 ; \mathrm{p}>.05)$. The results of the posttraining phase of the study are summarized in Figure 1, which shows the mean saccharin consumption of all experimental groups on the posttraining test day. The posttraining test day consumption was analyzed using a 3 by 6 (concentration by delay) analysis of variance. Data from the $.9 \%$ (isotonic) $\mathrm{NaCl}$ group was omitted from the analysis because, as expected, all subjects in this group increased their saccharin consumption between the training and posttraining measures. By including their data in the analysis, the effects would have been spuriously inflated. The results of this analysis are given in Table 1, and show that on the posttraining test day both $\mathrm{NaCl}$ concentration and CS-UCS delay were significant effects. Individual comparisons on the 
amount consumed by the experimental groups and the pooled control $(.9 \%)$ group at each delay were made using independent $t$ tests. A summary of these comparisons is given in Table 2. From this table it can be seen that when the $12.15 \% \mathrm{NaCl}$ solution was intubated, aversions to saccharin water were obtained at all but the 24-h delay. When an $8.1 \% \mathrm{NaCl}$ solution was intubated, aversions were produced at delays up to $7 \mathrm{~h}$ but not at 13.5 or $24 \mathrm{~h}$. Finally, when the weakest $(2.7 \%) \mathrm{NaCl}$ concentration was used, aversions were produced only at $.5,1.5$, and $4.5 \mathrm{~h}$ but not at $7.0,13.5$, or $24 \mathrm{~h}$.

\section{DISCUSSION}

These results show that intubation of $\mathrm{NaCl}$ produces effects that are similar to those found with other toxins. First of all, aversions were produced when only one CS-UCS pairing was used even though there was a delay. Secondly, there was a very orderly gradient of effectiveness which appeared to be dependent on the concentration of $\mathrm{NaCl}$ used and on the CS-UCS interval. For example, $2.7 \% \mathrm{NaCl}$ produced aversions at delays up to $4.5 \mathrm{~h}, 8.1 \%$ at delays up to $7.0 \mathrm{~h}$, and $12.15 \%$ at delays up to $13.5 \mathrm{~h}$.

The present results are comparable with those reported by Kalat and Rozin (1971) as well as results from a study by Wright, Foshee, and McCleary (1971). Using intubation of $.15 \mathrm{M}$ lithium chloride as a UCS and one training trial Kalat and Rozin (1971) found aversions to sucrose at delays up to $3 \mathrm{~h}$. A group tested at $7 \mathrm{~h}$, however, did not show a reduced preference. This finding is similar to the results found in the present experiment with $2.7 \% \mathrm{NaCl}$. Wright, Foshee, and McCleary (1971) used cyclophosphamide as a toxin and three CS-UCS pairings at intervals up to $120 \mathrm{~min}$. They found that dosage level, CS-UCS delay, and the Dosage by Trials interaction significantly influenced the strength of the aversion. That is to say, aversions to saccharin

Table 1

Analysis of Variance on Saccharin Intake by Experimental Groups on the Posttraining Test Day

\begin{tabular}{lrrrc}
\hline Source & SS & df & MS & \multicolumn{1}{c}{ F } \\
\hline Delay (D) & 901.3 & 5 & 180.3 & $23.10^{* *}$ \\
Concentration (C) & 227.2 & 2 & 113.6 & $14.55^{* *}$ \\
D by C & 61.3 & 10 & 6.1 & $.79^{*}$ \\
Error & 913.1 & 117 & 7.8 & \\
\hline
\end{tabular}

*Not significant

$* * p<.00001$
Table 2

Individual Comparisons of Experimental Groups With the Pooled Control Group at All CS-UCS Intervals on the Posttraining Test Day

\begin{tabular}{ccccccc}
\hline & \multicolumn{6}{c}{ CS-UCS Delay (in h) } \\
\cline { 2 - 7 } Comparison & .5 & 1.5 & 4.5 & 7.0 & 13.5 & 24.0 \\
\hline $\begin{array}{c}2.7 \%-.9 \% \\
8.1 \%-.9 \%\end{array}$ & $* *$ & $* *$ & $*$ & n.s. & n.s. & $*^{\mathrm{a}}$ \\
$12.15 \%-.9 \%$ & $* *$ & $* *$ & $* *$ & $*$ & n.s. & n.s. \\
\hline $\begin{array}{l}12.7 \% \text { mean greater } \\
a_{p}<.05\end{array}$ & $* *$ & $* *$ & $* *$ & $* *$ & $*$ & n.s. \\
\hline
\end{tabular}

were strongest when the delay was $30 \mathrm{~min}$ and with a $75 \mathrm{mg} / \mathrm{kg}$ concentration of cyclophosphamide. Increases in delay interval and/or decreases in concentration served to weaken the aversion. Comparisons between aversions reported by Wright et al. and those reported in the present experiment indicate, however, that for comparable delay intervals, aversions disappeared more quickly with increases in CS-UCS interval and/or decreases in concentration when cyclophosphamide was used than when intubated $\mathrm{NaCl}$ was the UCS. It is possible that the steeper gradient with cyclophosphamide could have occurred because Wright et al. used three training trials. Altematively, it is possible that with the concentrations used, cyclophosphamide is a less effective toxin than stomach intubated $\mathrm{NaCl}$.

\section{REFERENCES}

Braveman, N. S., \& Capretta, P. J. The relative effectiveness of two experimental techniques for the modification of food preferences in rats. Proceedings of the 73rd Annual Convention of the American Psychological Association, 1965, 1, $129 \cdot 130$.

Capretta, P. J. An experimental modification of food preferences in chickens. Joumal of Comparative and Physiological Psychology, 1961, 54, 238-242.

Kalat. J. W., \& Rozin, P. Role of interference in taste aversion learning. Joumal of Comparative and Physiological Psy chology, 1971, 77, 53-58.

Revusky, $S$. $H$. The role of interference in association over a delay. In W. K. Honig and P. H. R. James (Eds.), Animal memory. New Yoxk: Academic Press, 1971.

Revusky, S. H., \& Garcia, J. Leamed associations over long delays. In G. H. Bower and J. T. Spence. (Eds.), The psychology of learning and motivation: Advances in research and theory (Vol. 4). New York: Academic Press, 1970.

Winer. B. J. Statistical principles in experimental design. New York: McGraw-Hil, 1962.

Wright, W. E., Foshee, D. P.. \& McCleary, G. E. Comparison of taste-aversion with various delays and cyclophosphamide dose levels. Psy chonomic Science, 1971, 22, 55-56.

(Received for publication January 3, 1975; revision accepted March 21,1975 .) 